\title{
DISLEXIA E AS DIFICULDADES DE APRENDIZAGEM NO CONTEXTO MULTIDISCIPLINAR À LUZ DA PSICOLOGIA COGNITIVA
}

\author{
Cristiane de Oliveira Vieira Souza ${ }^{1}$ \\ Diógenes José Gusmão Coutinho ${ }^{2}$
}

RESUMO: A Dislexia é um distúrbio de aprendizagem que afeta crianças em todos os níveis das séries iniciais, dificultando a leitura e a escrita e, por conseqüência sua compreensão, portanto torna-se importante saber o que é Dislexia, os tipos, quais os conceitos e os prejuízos causados no processo de aprendizagem e alfabetização. $O$ estudo apresentou como objetivo descrever a Dislexia, suas causas, distúrbios de aprendizagem, diagnóstico e tratamento, juntamente com sugestões de intervenções, e procurar saber se as professoras têm um conhecimento sobre a Dislexia em seu corpo de formação. Para atingir estas informações, foi realizada uma pesquisa de campo com aplicação de um questionário qualitativo com perguntas abertas destinada as professoras de níveis fundamentais, de uma escola da rede municipal de ensino, objetivando a importância de informações mais aprofundadas sobre a temática. Para compreender esta questão, foi realizada uma pesquisa descritiva compreendendo a problemática da Dislexia e suas dificuldades de aprendizagem, baseando-se em autores que discutem sobre a temática com riqueza de conhecimento teóricos e discursivas. A pesquisa apontou como resultados iniciais, professores que percebem em seus alunos a dificuldade de aprendizagem, relacionadas à leitura e escrita e o apontamento das causas que se atribui às mesmas. Identificou-se ainda que os professores desenvolvem alguns trabalhos diferenciados para atender as necessidades específicas dos alunos. Portanto, a criança que é diagnosticada com Dislexia precisa de intervenção psicopedagógica apropriada, para que sua capacidade e sua auto-estima se elevem, e com isso, o resultado se vê na sua aprendizagem.

Palavras-chave: Dislexia. Leitura. Escrita. Dificuldades de Aprendizagem. Intervenção.

ABSTRACT: Dyslexia is a learning disorder that affects children at all levels of the early grades, making reading and writing difficult and, consequently, understanding, so it is important to know what dyslexia is, its types, concepts and damage caused in the learning and literacy process. The study aimed to describe Dyslexia, its causes,

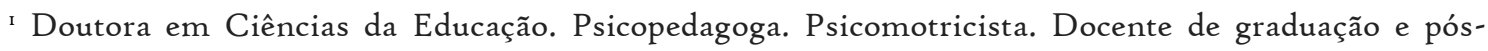
graduação.

${ }^{2}$ Doutor em biologia pela UFPE. Professor da Faculdade Alpha e Unibra. Orientador de dissertações e teses.E-mail: gusmao.diogenes@gmail.com.
} 
learning disorders, diagnosis, and treatment, along with suggestions for interventions, and to find out if the teachers have knowledge about Dyslexia in their training body. To reach this information, a field research was carried out with the application of a qualitative questionnaire with open questions aimed at elementary level teachers from a school in the municipal education network, aiming at the importance of more indepth information on the subject. In order to understand this question, a descriptive research was carried out, comprising the issue of Dyslexia and its learning difficulties, based on authors who discuss the theme with a wealth of theoretical and discursive knowledge. The research pointed out as initial results, teachers who perceive learning difficulties in their students, related to reading and writing, and pointing out the causes attributed to them. It was also identified that teachers develop some differentiated work to meet the specific needs of students. Therefore, the child who is diagnosed with Dyslexia needs appropriate psychopedagogical intervention, so that their capacity and self-esteem are raised, and with that, the result is seen in their learning.

Keywords: Dyslexia. Reading. Writing. Learning difficulties. Intervention.

\section{INTRODUÇÃO}

A pesquisa buscou levantar discussões acerca dos processos cognitivos dos alunos portadores de Dislexia, tendo como foco ao contexto escolar, em função da necessidade dos educadores em ampliar os conhecimentos e compreenderem como se dá o processo de aprendizagem das crianças, uma vez que essas dificuldades e os distúrbios de aprendizagem são apontados como os maiores desafios enfrentados em sala de aula atualmente.

Para abordagem de tal temática, levamos em conta a quantidade de crianças inclusivas com Dislexia em salas de aulas, apontando a falta de estratégias e conhecimento dos professores no que se refere a esta questão.

Torna-se justificável tais ações para delinear o conceito da Dislexia atualmente, bem como para orientar os professores a identificá-la, sem confundi-la com as dificuldades naturais que qualquer aluno "comum" encontra para ser alfabetizado. Pretendemos tornar acessíveis estas informações no sentido de orientar os professores para que em conjunto saibam agir de maneira correta e coerente ao se deparar com alunos que apresentam verdadeiramente este distúrbio de aprendizagem que interfere na dinâmica e no seu desenvolvimento escolar. 
Este estudo foi relevante diante da problemática existente do contexto escolar em que está inserido o aluno com essa patologia, contribuindo assim, para a prática pedagógica dos educadores oferecendo suporte necessário para intervenções adequadas bem como no auxílio à superação do fracasso escolar.

A partir do exposto, apresentamos como problematização o fato de o conhecimento sobre os distúrbios da Dislexia se tornar inerente ao aprendizado da criança. Vale salientar que as crianças com qualquer tipo de necessidade especial, devem ser incluídas naturalmente nas atividades em grupo, não esquecendo que tais crianças apresentam dificuldades específicas. Neste sentido, deve-se contar com o bom senso pedagógico, sensibilidade, formação e conhecimento do professor diante dos distúrbios.

$\mathrm{O}$ interesse em pesquisar sobre a temática em questão se deu mediante as queixas apresentadas pelos professores. Não é difícil o disléxico ser rotulado de irresponsável, burro, desleixado, deficiente mental ou incompetente, pela equipe de professores. Diante destas afirmativas, têm-se os seguintes questionamentos: Como os professores têm desempenhado sua função diante da Dislexia em sala de aula? Que resposta (ao menos provisória) já tem para a pergunta? O que imaginamos que vamos encontrar em termo de resultado? Que resultado pode gerar?

Para responder a esses questionamentos buscamos alcançar como objetivo geral dessa investigação: verificar quais as dificuldades enfrentadas por professores no trato pedagógico com crianças diagnosticadas com Dislexia. E como questões específicas elencamos: Analisar as concepções dos professores sobre Dislexia, seu conceito e suas nuances no contexto da sala de aula; verificar como fazer a adequação do processo avaliativo nos alunos com Dislexia no contexto da sala de aula, considerando as dificuldades de aprendizagem ao avaliar os alunos com Dislexia e, por fim, identificar quais as concepções dos professores sobre Dislexia, assim os questionamos e respondemos sobre o que é Dislexia.

Espera-se que a pesquisa possa ajudar os profissionais a construir uma consciência social voltada para as diferentes realidades, e ressaltar estratégias com uso de jogos, na perspectiva de uma abordagem multissensorial, gerando uma curiosidade 
entre os docentes para se informar mais e terem a sua opinião formada, assim como oferecer aos alunos uma aprendizagem mais significativa e adequada.

\section{METODOLOGIA}

Este estudo está caracterizado por uma pesquisa de campo, de natureza qualitativa, onde o material coletado foi fichado e selecionado para ampliação dos conhecimentos acerca da Dislexia e suas nuances, as quais impedem que o processo de aprendizagem da criança se desenvolva com eficácia, o que não exclui a revisão de literatura necessária a uma abordagem das categorias aqui apresentadas.

Portanto, o uso dessa abordagem qualitativa se deu porque a mesma procura compreender os fenômenos segundo a perspectiva dos sujeitos, ou seja, dos participantes da situação em estudo. Segundo Minayo (1995, p. 21-22):

A pesquisa qualitativa responde a questões muito particulares. Ela se preocupa, nas ciências sociais, com um nível de realidade que não pode ser qualificado, ou seja, ela trabalha com o universo de significados, motivos, aspirações, crenças, valores e atitudes, o que corresponde a um espaço mais profundo das relações dos processos e dos fenômenos que não podem ser reduzidos à operacionalização de variáveis.

A pesquisa teve como sujeitos participantes duas (2) professoras da rede municipal de ensino, onde aplicamos como instrumento de coleta de dados da pesquisa um questionário que teve como objetivo conhecer a Dislexia do ponto de vista destes profissionais da área de educação.

O critério de escolha das professoras que participaram deste estudo é que fossem do Ensino Fundamental de escola pública.

As questões foram todas respondidas por escrito por cada uma das docentes, composto por io questões abertas que tratam do tema em questão.

Nesta perspectiva, e de acordo com Richardson (1999 p. 205):

[...] o questionário permite obter informações de um grande número de pessoas, relativa uniformidade de informações, facilidade de tabulação dos dados e abrangência de amplas áreas geográficas em tempo relativamente curto.

Segundo Lakatos (1992, p.44), a pesquisa possibilita compreender a resolução de um problema a ser obtido através dela e é o primeiro passo para todo e qualquer trabalho científico. 


\section{RESULTADOS E DISCUSSÕES}

Este estudo se desenvolveu através de dados coletados pelos (2) questionários contendo (Iо) perguntas, realizados com as professoras do Ensino Fundamental, uma vez que elas estão diretamente em contato com os alunos, detectando se realmente estes mostram a dificuldade biológica e se é passada da maneira adequada do uso dos recursos para a melhoria do desenvolvimento do aluno Disléxico.

O roteiro da entrevista foi composto por questões abertas, dando oportunidade às professoras de responder as questões expondo como elas veem o distúrbio da Dislexia, como conceitua e seu prejuízo no processo de aprendizagem dos alunos.

Neste estudo as professoras são chamadas de Professora A e Professora B, por serem de unidades educacionais diferentes. O perfil das professoras participantes da pesquisa pode ser conferido conforme o quadro abaixo:

Quadro I - Perfil dos sujeitos da pesquisa

\begin{tabular}{|c|c|c|c|c|c|}
\hline Professoras & Idade & Sexo & $\begin{array}{c}\text { Experiência } \\
\text { Profissional }\end{array}$ & $\begin{array}{c}\text { Formação } \\
\text { Inicial }\end{array}$ & $\begin{array}{c}\text { Formação } \\
\text { Continuada }\end{array}$ \\
\hline A & 26 & Feminino & 5 Anos & Magistério & $\begin{array}{c}\text { Cursando } \\
\text { Pedagogia }\end{array}$ \\
\hline B & 35 & Feminino & 8 Anos & Magistério & $\begin{array}{c}\text { Pedagogia } \\
\text { Educação } \\
\text { Especial }\end{array}$ \\
\hline
\end{tabular}

Fonte: Questionário

As respostas apresentadas pelas professoras foram analisadas individualmente. Observou-se que entre um ponto e outro houve algumas considerações que se afastaram do objeto de estudo.

Embasados na compreensão teórica dos autores acima destacados, nosso estudo buscou compreender quais as concepções dos professores sobre Dislexia, assim os questionamos sobre o que é Dislexia para tais profissionais. 
De acordo com as respostas das professoras, observou-se ainda que independentemente de não ter participado de algum curso específico na área, à professora B conseguiu registrar seus conceitos em parte, razoavelmente, dentro de algumas características comprovadamente de Dislexia, conceituando-a conforme: "Dislexia é um transtorno na aprendizagem na qual se torna uma dificuldade para o aluno no conhecimento de símbolos e fonemas”.(Professora B)

Enquanto a concepção da outra professora foge da conceptualização do termo e reporta sua consideração a outras considerações, no tocante aos distúrbios de aprendizagem conforme: "Detectando a Dislexia, cabe à escola, juntamente com o professor trabalhar este aluno de forma "distinta" para fazer com que ele consiga amenizar seu distúrbio de aprendizagem”. (Professora A).

Observou-se que as professoras pesquisadas, reportaram na sua fala uma disparidade do conceito de Dislexia. Desta forma, percebeu-se que a professora $\mathbf{A}$ não tem um conhecimento real do que vem a ser Dislexia, e vale ressaltar que este conceito se aproxima das queixas principais dos professores nas salas de aulas atualmente, pelo fato dos alunos das séries iniciais não aprenderem a ler e escrever em tempo hábil. A Dislexia, de acordo com Associação Brasileira de Dislexia (ABD), é um distúrbio neurológico das habilidades de leitura e de escrita, e verifica-se que apenas a professora (A) definiu como um distúrbio de leitura que causará um distúrbio de escrita e há outros fatores a serem observados.

As professoras também foram questionadas se reconhecem uma criança disléxica; a professora $\mathbf{A}$ disse que não e a $\mathbf{B}$ disse que sim.

De acordo com os teóricos estudados, dentre eles Calafange (2004) e Martins (2003):

\footnotetext{
O termo dislexia é aplicável a uma situação na qual a criança é incapaz de ler com a mesma facilidade com a qual lêem seus iguais, apesar de possuir uma inteligência normal, saúde e órgãos sensoriais intactos, liberdade emocional, motivação e incentivos normais, bem como instrução adequada.
}

Ao reportar ao termo "distúrbios de aprendizagem" recorrente nos estudos que tratam da Dislexia, elegemos como questão fundamental identificar como as professoras relacionam a Dislexia e os Distúrbios. Assim perguntamos se elas viam a Dislexia como um Distúrbio de aprendizagem. 
Com base nas respostas obtidas, as professoras sugerem métodos eficazes, lembrando que não existe um único método específico, mas sim, vários métodos para que o indivíduo com Dislexia possa ter uma aprendizagem significativa. Assim confirmado: "O professor tem que desenvolver técnicas didáticas para estimular o interesse do aluno, começando pelo ensino aprendizagem”. (Professora A). "É a pessoa que apresenta dificuldades em aprender". (Professora B).

Conforme verificou-se nos trechos das falas, a professora B apresentou uma alusão às dificuldades dos alunos, enquanto a outra professora não faz referência nem relação com os termos. De acordo com Martins (2003):

O primeiro fator essencial para o desenvolvimento da capacidade de aprender é motivar os alunos e o próprio aluno querer aprender, ter interesse, atenção, compreensão, participação e expectativa de aprender a conhecer, a fazer, a conviver e a ser pessoa. O segundo fator é o desenvolvimento de aptidões cognitivas e procedimentais; aprender métodos e técnicas de estudo para garantir a capacidade de autoaprendizagem. O terceiro fator é a aprendizagem de conhecimentos ou conteúdos, ou seja, a construção de um currículo escolar é fundamental para que o aluno desenvolva sua compreensão do ambiente natural, social e também da tecnologia, das artes e dos valores em que se fundamenta a sociedade.

Uma criança com dificuldades de aprendizagem é uma criança que terá um desenvolvimento mais lento do que outras, de acordo com Associação Brasileira de Dislexia (ABD), isto é:

Distúrbios neurológicos das habilidades de leitura e de escrita, enquanto apenas um professor a definiu como um distúrbio de leitura que causará um distúrbio de escrita, ou seja, o fato de deparar com alguns desses sintomas não advertir fundamentalmente que a criança seja disléxica; há outros fatores a serem observados.

Por esse motivo, não deve-se diagnosticar essa criança como deficiente ou inapta, crianças com dificuldades de aprendizagem podem aprender a ler e escrever com o suporte do professor, usando técnicas didáticas em um processo significativo de aprendizagem na sala de aula. Segundo Zorzi (2008), “o disléxico possui peculiaridades em sua maneira de aprender e os profissionais de educação devem estar aptos a reconhecer tais dificuldades e auxiliá-lo ao desenvolvimento da sua aprendizagem”.

Optou-se por indagar às professoras se elas conhecem os sinais de alerta para um possível diagnostico da Dislexia. Mediante as respostas afirmadas das professoras, 
os disléxicos possuem dificuldades de aprendizagem na leitura e na escrita, em soletrar sons, podendo aprender conforme os outros alunos, só com uma diferença que é o ritmo "lentidão", mas alguns vencem as dificuldades da aprendizagem com maior facilidade do que outras crianças.

Segundo Martins (2003),

A dislexia é uma dificuldade específica de leitura. É um transtorno inesperado que professores e pais observam no desempenho leitor da criança. Os sintomas da dislexia podem ser observados no ato de ler, de escrever ou de soletrar.

Uma criança apresenta características marcantes na dificuldade de aprendizagem, principalmente na acumulação e persistência de seus erros ao ler e escrever, em soletrar sons, os problemas mais comuns são os seguintes segundo Condermarin (1986)

- Confusão entre letras, sílabas ou palavras com diferenças sutis de grafia: a-o; c-o; e-c; f-t; h-n; v-u; etc.

- Adições ou omissões de sons, sílabas ou palavras: famoso substituído por fama; casa por casaco.

- Alterações na memória: algumas crianças apresentam dificuldades para lembrança imediata de fatos passados, não conseguem lembrar palavras ou sons que escutam, têm dificuldade em memorizar visualmente objetos, palavras ou letras.

As características apresentadas pelas professoras estão coerentes com o que dizem os teóricos a respeito do assunto, ou seja, as mesmas citaram algumas características: mas enfatizou-se que há outros fatores a serem observados. " $\mathrm{Na}$ eventualidade de identificar vários sintomas de alerta e a criança manifestar dificuldades significativas no processo de leitura e escrita". (Professora A) e "Trocas de letras e dificuldades na leitura". (Professora B)

Indagou-se também junto aos professores sobre o conhecimento da equipe que é habilitada a realizar o diagnóstico da Dislexia, compondo uma equipe multiprofissional. $\mathrm{Na}$ concepção das professoras os profissionais habilitados a realizarem o diagnóstico da Dislexia, é multidisciplinar que inclui o Médico, Psicólogo, Psicopedagogo, Fonoaudiólogo e o Neurologista.

De acordo com as respostas apresentadas pelas professoras, constatou-se que as mesmas têm um conhecimento prévio da forma correta para o diagnóstico das 
crianças com dificuldades na leitura e na escrita conforme o trecho: "Psicólogo, Psicopedagogo, Fonoaudiólogo e Neurologista”. (Professora A) e “O psicopedagogo”. (Professora B)

Destacando que o Psicopedagogo Clínico é o profissional que inicia a investigação detalhada e verifica a necessidade do parecer de outros profissionais, como o Oftalmologista. Conforme o caso é muito importante o parecer da escola, dos pais, o levantamento do histórico familiar e a evolução do aluno. Segundo a Fonoaudióloga e psicopedagoga Sônia Maria Pallaoro Moojen:

\begin{abstract}
A intervenção do psicopedagogo ou fonoaudiólogo tem o objetivo de levar o disléxico a reencontrar-se consigo mesmo, a partir de mudanças do sistema motivacional, e vai variar conforme o tipo de dislexia: fonológica, lexical ou mista. $\mathrm{O}$ resultado esperado é favorecer um controle emocional durante a leitura e auxiliar para que tenha uma boa imagem de si mesmo e consiga conviver com as dificuldades. Partindo de textos curtos, interessantes e lidos de forma conjunta, o profissional deve possibilitar que a leitura desperte sentimento positivo no disléxico, auxiliando a melhorar a capacidade para operar com as regras que relacionam fonologia, ortografia e trabalhando a compreensão de texto, além de criar redes com a escola e a família.
\end{abstract}

É importante analisar o plano de tratamento que varia de criança para criança,

e ressaltando que não há um único método de tratamento, mas o professor pode facilitar a vida escolar de um disléxico tomando algumas atitudes juntamente com a equipe multiprofissional.

Nesse contexto, foi importante apreender das professoras o sentido que elas dão à escola a partir da contribuição que, juntamente com os pais, podem dar aos disléxicos. Assim indagou-se aos professores sobre a importância dessas duas instituições no desenvolvimento das crianças.

De acordo com as respostas das professoras, os pais são importantes no trabalho educativo dos alunos. Eles devem estar atentos para o desenvolvimento da linguagem e a alfabetização da criança, da mesma forma que é importante diagnosticar a Dislexia é importante que não aja estigmatizarão da criança e nem superproteção pelos pais. "Usar exercícios criativos que envolvam a memória, tais como recitar poemas, utilizar mímica, teatro, falar de imagem, jogos a pares, cantar música”. (Professora A) e “Dá suporte ao professor e ao psicopedagogo". (Professora B) 
Os pais devem observar a criança ao ler e ao escrever, fazendo com que a mesma articule cada fonema, vogal e consoante, aconselha-se que os pais leiam em voz alta, utilizem jornais, revistas e livros para despertar o interesse. Os pais juntamente com a escola têm o papel de dá estimulo ao disléxico, fazendo com que não desista, tranqüilizando e ressaltando a sua esperteza e sua inteligência e que possa desenvolver suas habilidades.

Em caráter de conclusão Frank (2003, p.95), deixa-nos esta mensagem a todos os pais e educadores:

A dislexia é uma dádiva?... se isso é um presente, quero desenvolver o meu. Todos nós temos questões pessoais e profissionais as quais precisamos trabalhar e melhorar, ao longo de nossa existência. Não conheço ninguém que esteja perfeitamente satisfeito com todos os aspectos de vida. Esforçando-nos diariamente para melhorarmos as relações com nosso cônjuge ou parceiro, para fortalecermos os laços com os filhos, para nos comunicarmos com mais eficiência com os colegas de trabalho ou para usarmos o tempo de maneira mais profunda e eficiente. Desenvolver estratégias para melhorar em várias áreas é uma constante procura humana. Para conquistar o que se quer na vida, é preciso correr riscos e enfrentar desafios. Lidar com a dislexia não é diferente. [...] Como tudo o mais, é preciso muito empenho, comprometimento, criatividade e tempo para desenvolver maneiras de melhorar.

A Constituição Federal, no seu artigo 205 (1998), e a Lei de diretrizes e bases

(LDB, 1996), no seu artigo 2, afirmam que:

A educação é dever da família e do Estado. A família é convocada pelo poder público a participar do processo de formação escolar: no primeiro momento, matriculando, obrigatoriamente, seu filho, em idade escolar, no Ensino Fundamental. No segundo momento, zelando pela freqüência à escola e num terceiro momento se articulando com a escola de modo a assegurar meios para a recuperação dos alunos de menor rendimento e zelando, com os docentes, pela aprendizagem dos alunos.

Os dados obtidos mostraram que as professoras entrevistadas não estudaram sobre a Dislexia em seu curso de formação, mas encontram ou já encontraram entre seus alunos crianças com dificuldades de aprendizagem e com Dislexia. Possuem diferentes limitações em como trabalhar em sala de aula com tais, crianças e sendo assim, encaminham seus alunos disléxicos a outros profissionais (que a escola disponibiliza), esperando deles orientações para desenvolver seu trabalho em sala de aula. 


\section{CONSIDERAÇÕES FINAIS}

Com a realização dessa pesquisa percebeu-se que a escola não está totalmente apta para receber o aluno disléxico, uma vez que nem sempre o professor tem o conhecimento específico necessário sobre esse tema na formação acadêmica, dificultando a aprendizagem de um disléxico. Observamos também que a escola não possui os recursos adequados para o aprendizado dos alunos.

Foi identificado também nesta pesquisa que cada vez o professor precisa buscar aperfeiçoar-se para que possa desenvolver um trabalho significativo com todos os alunos, facilitando os diversos tipos de problemas de aprendizagem que aparecem em sala de aula, como o que trabalhar com uma criança disléxica e quais as estratégias utilizadas para transmitir um conhecimento e aprender com os demais, ajudando na construção de melhores formas de aprendizagem. Pôde-se destacar que os professores necessitam mais informações sobre este assunto, e de que maneira possa ser trabalhado para minimizar as dificuldades que os alunos possuem no ambiente escolar, pelo fato de muitos pais não participar efetivamente da vida ativa de seus filhos.

Mediante os estudos, a Dislexia não consegue o resultado e a superação imediata, necessita que os pais e os professores estejam sempre atentos e sensíveis aos sinais, para que possam intervir, buscando recursos e meios para garantir metas e atingir os melhores objetivos, juntamente com esta criança a equipe multiprofissional, para que a mesma tenha o prazer em desenvolver suas atividades. Faz-se necessário que as escolas se preparem para acolher esses alunos de forma que tenha uma relação específica e o domínio da aprendizagem individualizada.

Por fim, é importante citar que esta pesquisa aponta o quanto é importante que o professor também domine o estudo ao menos que básico teórico e prático dos distúrbios de aprendizagem, sugerindo uma urgente revisão e uma reformulação dos currículos que norteiam a formação dos estudantes de pedagogia, proporcionando aos seus formandos a capacidade de atuar com os distúrbios de aprendizagem e com todos os segmentos educacionais. 


\section{REFERÊNCIAS}

ABD - Associação Brasileira de Dislexia. Disponível em: <http//www.dislexia.org.br. Acesso em: 2016.

CAFALANGE, Selene. Dislexia... Ou Distúrbio da Leitura e da Escrita, Disponível em: <http//www.eduk.com.br. Acesso em: 2016.

CAPOVILLA, Fernando César. Neuropsicologia e Aprendizagem: Uma abordagem multidisciplinar. $2^{\mathrm{a}}$ ed. São Paulo: Memnon, 2004.

CONDERMARIN, Mabel. Dislexia: Manual de leitura corretiva. Porto Alegre: Artes Médicas, 1986.

CONSTITUIÇÂO: República Federativa do Brasil. Brasília: Senado Federal, Centro Gráfico, 1998.

CRUZ, V. Dificuldades de Aprendizagem Específicas. Lisboa: LIDEL - Edições Técnicas, Lda. 2009.

FILHO, C. R. C.. Jogos Matemáticos para estimulação da inteligência nos distúrbios de Discalculia. (2007) Disponível em http://www.webartigos.com/articles/2067/I/Jogos-Matemaacuteticos-Para- -NosDistuacuterbios-De-Discalculia/paginar.html\#ixzzIJnDUXM53. Acesso em 2017.

FRANK, R. LIVINGSTON, Kathryn E. A vida secreta da criança com dislexia, Como ela pensa. Como ele sente. Como eles podem ser bem sucedidos. São Paulo: M. Books do Brasil, 2003.

GIL, Antônio Carlo. Como Elaborar Projetos. $5^{\underline{a}}$ ed. 8ํㅜ reimpr. São Paulo: Atlas, 2010. 
LAKATOS, Maria Eva. MARCONI, Maria de Andrade. METODOlOGIA DO TRABALHO CIENTÍFICO / 4 ed-São Paulo. Revista e Ampliada. Atlas, 1992.

MARTINS, Vicente. Dislexia. Disponível em: http://sites.uol.com.br/vicente.martins. Acesso em 2017.

MINAYO, M. C. S. O Desafio do Conhecimento: pesquisa qualitativa em saúde. São Paulo: Hucitec, Rio de Janeiro: Abrasco, 1992.

MOOJEN, Sônia Maria Pallaoro: A escrita ortográfica na escola e na clínica: teoria, avaliação e tratamento. $2^{2}$ ed. Casa do Psicólogo, São Paulo, 20 Ir.

ORTON, Samuel. A Psicopedagogia e Ensino da Arte. São Paulo: Artes Médicas, 200 I.

PEREIRA, R. S. Dislexia e Disortografia - Programa de Intervenção e Reeducação (vol. I e II). Montijo: You!Books. 2009.

REBELO, J. A. Dificuldades de Aprendizagem em Matemática: as suas relações com problemas emocionais. Coimbra: Revista Portuguesa de Pedagogia. 1998a.

RELVAS, M. P. Neurociência e Transtornos de Aprendizagem. $5^{\text {a }}$ ed. Editora Wak. Rio de Janeiro, 2oII.

RICHARDSON, R. J. Pesquisa social: métodos e técnicas. São Paulo: Atlas, I999.

RIEF, S. \& HEIMBURGE, J. Como ensinar todos os alunos na sala de aula inclusiva: estratégias prontas a usar, lições e atividades concebidas para ensinar alunos com necessidades educativas especiais de aprendizagem diversas (vol. I). Coleção Educação Especial. Porto: Porto Editora. 2000. 
ROTTA, Newra Tellecha. Transtornos da Aprendizagem: Aborda Neurológica e Multidisciplinar. Artmed, Porto Alegre, 2006.

SILVA, F. T. G. T. Lado a Lado - Experiências com a Dislexia. Coleção Educação Hoje. Lisboa: Textos Editores. 2004.

SOUZA, E. M. Problemas de Aprendizagem - Crianças de 8 a II anos. Bauru: EDUSC, 1996.

TORRES, R. \& FERNÁNDEZ, P. Dislexia, Disortografia e Disgrafia. Amadora: McGraw-Hill. 2oor.

VALLET, Robert E. Dislexia: uma abordagem neuropsicológica para a educação de crianças com graves desordens de leitura. São Paulo, 1989.

ZORZI, Jaime. Guia prático para ajudar crianças com dificuldades de aprendizagem: dislexia e outros distúrbios. SP: Editora Melo, 2008.

O Papel do Psicopedagogo ou Fonoaudiólogo e da Escola. Disponível em: http://dislexicosaibaseusdireitos.blogspot.com.br/2008_o4_or_archive.html Acesso em 2016. 